\title{
The Main Melody Movie and TV Drama Participate in Ways of Innovation to Ideological and Political Education for College Students under New Situation Conditions
}

\author{
Feng Qin ${ }^{1}$ \\ ${ }^{1}$ Department of Facility and Laboratory Management. \\ Guangxi University for Nationalities \\ Guangxi University for Nationalities, gxun \\ Nanning, China \\ qinfengxiren@126.com
}

\author{
Ning Yang ${ }^{2}$ \\ ${ }^{2}$ Party Committee Office. Guangxi Open University \\ Guangxi Open University, gxou \\ Nanning, China \\ yangning9521070@163.com
}

\begin{abstract}
As the film and television works which reflect society specific values and character of people in social history and practice under the leadership of the party, the main melody movie and TV drama makes the audiences to get an education subliminally when they are enjoying sensual pleasure. From the angle of special media-the Main Melody movie and TV drama, investigate the issues about how to innovate the routes of ideological and political education for college students in the environment of information age.
\end{abstract}

Keywords-the main melody movie and TV drama; ideological and political education for college students; routes

\section{INTRODUCTION}

The current era is both the information age and the media era, the highly developed mass media machine transmit vast amounts of information to the special group-college students through different media formats, the awareness and judgment of college students to the external world to a certain extent directly depend on information and quality of receiving and dealing with the information they obtained. The film and television works make use of the information processing as stereo processing of sound, color, with the methods "sensory impact and emotion permeate" to directly or indirectly convey knowledge, skills, thinkings, values to the object of education, they cater to the recreational and consumption characteristics of college students, make the educatee to get an education subliminally when they are enjoying sensual pleasure. In order to improve the quality of ideological and political education for college students, this article investigate the issues about how to innovate the routes of ideological and political education for college students in the environment of information age from the angle of special media-the Main Melody movie and TV drama.

\section{THE NECESSITY AND FEASIBILITY OF DEVELOPING “THE MAIN MELODY MOVIE AND TV DRAMA” AS RESOURCE OF IDEOLOGICAL AND POLITICAL EDUCATION FOR COLLEGE STUDENTS}

College students are active practitioner of " China dream" , universities should "Always persevere in arming the people with scientific theories, guiding the people with correct media guidance, imbue them with lofty ideals, and inspire them with excellent works ", purposefully and wittingly guide them closely linked personal ideals to the fate of country and nation consciously when developing ideological and political education resource. Under the new situation, Information and communication technologies are developing leaps and bounds, melody movie and TV drama are sweeping the globe with lightning speed, it serve as a living close friend of most people. The main melody movie and TV drama is a special and efficient media which takes on transmitting social "positive energy", it has rich content, diversified forms and amazing propagation velocity, it has strong unique charm, so it must complexly and far-reaching impact the learning, life, work of college students.

\section{A. "the main melody movie and tv drama" is the inherent requirement of innovating the routes of ideological and political education for college students}

Comrade Jintao $\mathrm{Hu}$ put forward in reports to the 18th national congress of CPC: "In order to develop a strong socialist culture in China, we must take the road cultural development of socialism with Chinese characteristics, adhere to the direction of serving the people and socialism, insist on the policy of "letting a-hundred flowers bloom, a-hundred 
schools of thought contend and the principle of pressing close to reality, life, and the masses, promote the all-round development of socialist spiritual and material civilization, building socialist culture toward modernization, the world and the future, national, scientific and popular." "In order to develop a strong socialist culture in China, the key is to enhance the cultural creativity of the whole nation. We must deepen cultural cultural system reform, liberate and develop cultural productivity, promote academic democracy, artistic democracy, provide a broad cultural stage to people, give full play to all sources of cultural creation to create full play the cultural creativity of the whole nation and to create a new situation which give an expression of cultural creativity of the whole nation sustained bursting, more colorful social and cultural life, people's basic cultural rights and interests better protecting, people's ideological and moral qualities, scientific and cultural quality of the overall improvement, the international influence of chinese culture's growing." ${ }^{[1]}$ Since 1992,the Propaganda Department of the Central Committee of the CPC have carried out selection activities "five one-good's project" annually, in other words, in order to raise the level and quality of spiritual civilization and ethics in China, we must expect making good use of a good drama, a good TV drama, a good book, a good theory article.

In accordance with this spirit, in recent years, more than 60 great main melody movie and TV drama have been concentratedly exhibited in CCTV TV series channel such as "Draw the Sword", "Rush to Northeast", "When We Were Young" , "The five-star red flag is fluttering in the wind" , " country fortune", "national heroes", "Fire Blue Blade” , “General Su Yu” , “Marshal Liu Baicheng” and so on, they have leaded college students to "arming the people with scientific theories, guiding them with correct public opinions, shaping their outlook with noble ideas, and inspiring them with good cultural works ". ${ }^{[2]}$ They have become good materials to ideological and political education for college students while they were well received a widespread social high opinion.

So-called the main melody movie and TV drama refers to the film and television works which are reflects specific social values, party's view, and about landmark characters and events in period of socialist construction reform and opening period which are under the leadership of the Communist Party of China. these works both carried feelings of patriotism which is about the Communist Party of China pledged their lives for national independence, a strong and prosperous and a great national spirit-self-improvement, unity and struggle, dedication, and reflected characters of people in the practice of social history under the leadership of the Communist Party of China. Therefore, the main melody movie and TV drama is one of the most direct, concentrated manners which from ideological penetration and national spirit of cohesion.

\section{B. "the main melody movie and tv drama" is a advantage platform of resource development to ideological and political education for college students}

Indubitability, influence to audients from the film and television works can't replace those from text reading, but on the means of ideological and political education for college students, the film and television works have greater incomparable advantages than those of text reading, on account of that the formation of rational thought is on the premise of capturing information from object by ears, eyes and other senses and of getting perceptual knowledge, and then thought processing by brain, and complicated psychological activities afterwards, eventually form some kind of value judgment. As a material carrier of intellectual products, the film and television works is a synthesized artistic form which is a integrative amalgamation by multiple language systems, such as sound, images, photography, emotions poured out. It starts from mobilizing audience's senses, personalized select, judge and process the predetermined information material, it veers educational pattern from traditional call type and inculcationtype, break time and space constraints of receiving information of audients, by the way of ideological infiltration-type, emotional experience-type and absorption-type, it subtly, ingeniously transmits the certain values ideological feeling bases on respecting and retaining the space of appreciation and consideration of audients, it makes the due morality of audients to be obtained and gradually risen imperceptibly. withal, Lenin have said: "In all the arts, the film is most important for us", " movies have affected public in the spirit of extraordinary ability” [3]

With the development of science and technology, network, such as the rapid development of new media carrier, the dominance of the traditional media, such as newspaper, magazine, radio, TV etc were broken, but media of the film and TV also occupy dominance in major mediums by virtue of its full-featured characteristics such as auditory and visual neural function, broad coverage and High contact rate.

According to the survey report, nationwide television broadcasting coverage rates covering 95.8 percent of the population in 2005, residents spend an average of 2 hours and 39 minutes a day in $\mathrm{TV}$, it is $46.22 \%$ of the total leisure time, watching TV is the activity which occupies the most leisure time. Urban population already reach more than $50 \%$ of total population by 2010 , the most popular form of entertainment of urban population is watching $\mathrm{TV}(84.5 \%)$,reading newspapers and magazines $(56.9 \%)$, they ranked in the top two overall in the 30 cities $^{[4]}$.

In addition, in April 2008, a media literacy group that come from Nanchang University Humanities and social sciences projects in 2005- "Study on media literacy education for college students" A survey on media literacy of Nanchang University college students were carried out up and down several times, a set of statistical data is obtained as follows: 

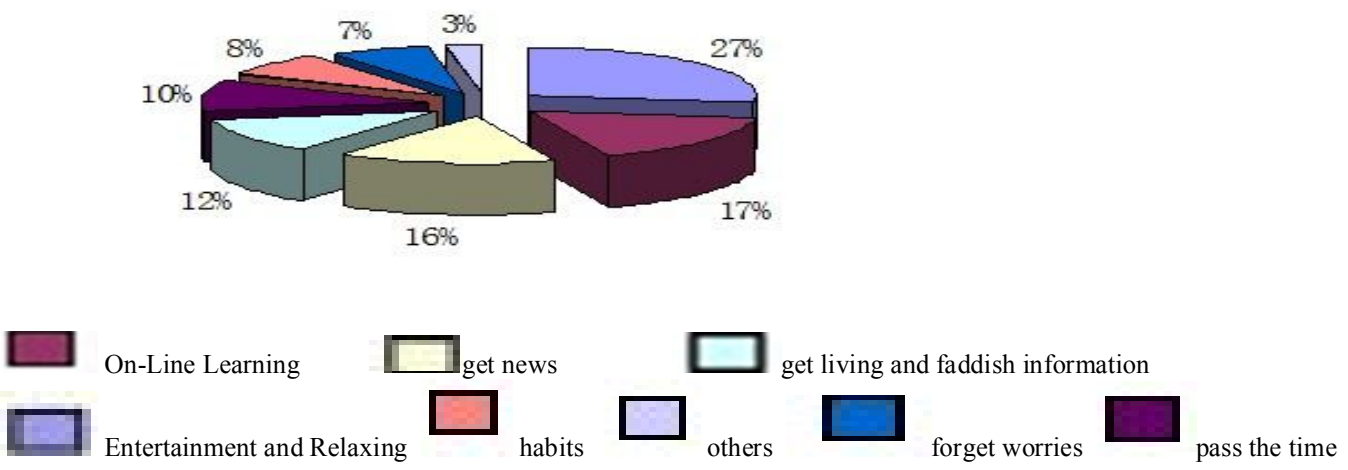

Fig.1. The purpose of college students contact network

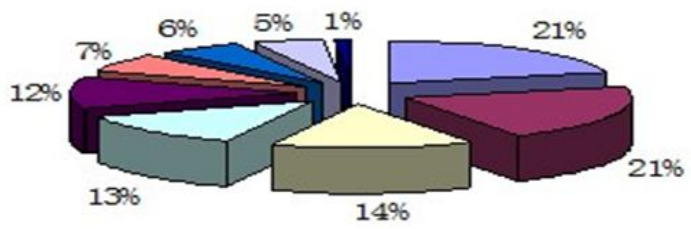

$\square$

On-Line Learning

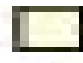

download

ए Read the news

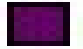

play games

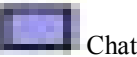

browse BBS posts

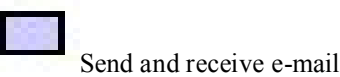

Write micro-blog or blog

Fig. 2. The present usage of network function of college students

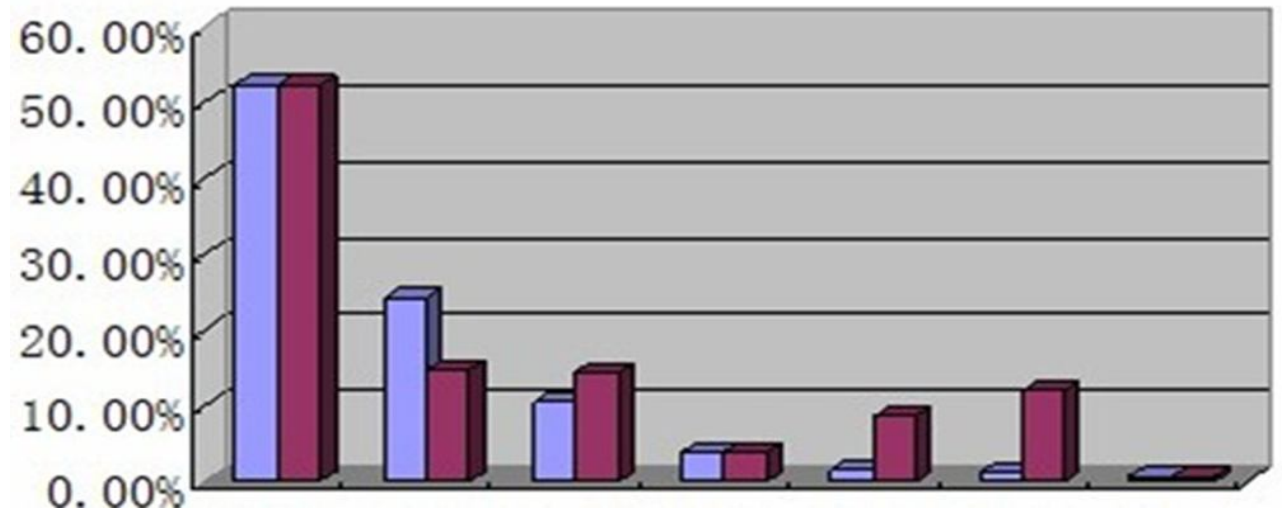

Network books television newspaper magazine movie broadcast

Fig. 3. The use of new media analysis of the present situation of college students.

Network books television newspaper magazine movie broadcast

Preference of audio-visual media

favorite medium 
Therefore, through several sets of survey data, we can get to a conclusion that we should strengthen and consolidate the principal position of television in putting around and carrying forward the national spirit.

\section{THE DEVELOPMENT FUNCTION THAT THE MAIN MELODY MOVIE AND TV DRAMA SERVES IN IMPROVING THE IDEOLOGICAL AND POLITICAL EDUCATION FOR COLLEGE STUDENTS}

According to the spirit on building a harmonious culture of the Party Central Committee, since 2005, it totally appeared prosperity as "Let a hundred flowers blossom, let a hundred schools of thought contend" to creation in television drama in our country, many works payed more attention to exploiting the subject connotation, shaping the real busty arts, it changed artistic mode as the previous single political propaganda lecture and "lofty, noble, perfect" characters, expanded the influence in the audiences on red film and television drama, $\mathrm{i}$ mperceptibly realized transformation to world outlook and values of college students, while they were playing role in values guidance. These Features further highlighted the development function that the main melody movie and TV drama serves in improving the ideological and political education for college students.

\section{A. Transfer positive energy, strengthen the ideal and faith of college students}

In the 18th national congress of CPC report, there is a series of new assertions: "To strengthen the construction of socialist core value system. Extensively conduct ideal and belief education, the people should be rallied closely under the great banner of socialism with Chinese characteristics" [5] college students are lacking in selection and judging to positive values in the pioneering stage of their, ideal and belief is just about the important content in the main melody movie and tv drama, therefore, it should be done that guiding them to set up firm ideal belief especially political belief, gradually cultivating thoughts and feelings to loving the party and supporting the party, going with party, ultimately, establishing a strong belief in the struggle for communism through the classic themes about ideal and belief on college students' ideal and faith education in " the main melody movie and TV drama ".It is described that a large number of scientists represented by Qian xuesen, Qian sanqiang overcome poor difficulties, tighten their belt, clenched their teeth, successfully developed atomic and hydrogen bombs, successfully launched man - made satellite, national miracle "two bombs and one satellite" were created and made in $<$ country fortune $>$, these feats shocked the world, country fortune is flourishing with each passing day. Provide a reference to the process of establishing values to those college students lack of responsibility with the similar episodes of assuming to achieve great "China dream" in their studying, lives and jobs, meanwhile, transmit "China dream" which is about Chinese national circle of life, constantly seeking and untiringly struggling to contemporary college students. It contributes to Firmly establish the belief "more play, more of a growth” .

\section{B. Exert the appeals of the main melody movie and tv drama, promote patriotism education for college students}

Patriotism education is the main theme of ideological and political education for college students. the mainstream film and television works Itself is the typical text to spirit of patriotism, and thus shaped and converged a vast lot of lofty images to heroes and heroines of the chinese nation and the classic patriotic stories about their fighting dauntlessly and dying bravely for national independence and the liberation of the people, reproduced many scenes that move people to song and tears, it also conveyed a deep patriotism feelings to college students which made them to realize that The happy life we have today was not easily won. Only college students know true to life about the past, present and future of their motherland can they produces a deep affection for the motherland from the cockles of their heart. For example, after watching the TV drama program "Draw the Sword" , many college students were in the melting mood by another and yet another actor's lines "attack, squadron" in the war against japan, especially captain Sun Desheng still shout" attack, squadron" even nobody is alive but himself only, the character do the best interpretation to the connotation of patriotism with killing into the enemy positions singlehandedly, gave college students deep feelings towards the sword spirit "Even in the face of strong opponent, we should resolutely sword even know well defeat. Even fall down, we still struggled to be a mountain, a ridge” .

\section{Carry forward model demonstration effect of the main melody movie and tv drama, promote honor versus dishonor view patriotism education for college students}

According to maslow's hierarchy of needs, college students are at the terminative and intense stage of needing for affiliation, aesthetics, self-fulfillment. With the educational status improving, both their thinking, self-awareness and senior social emotion are grew rapidly, however, because due to weak control, they usually arise mentality of disconnection of cognition and behavior and are at the development state stage of disconnection of the ideal self and actual self, under these conditions, the main melody movie and TV drama can make use of the plot and characters of the TV drama program to supply a social context which make the individuality to be in the cultural atmosphere of psychological reflection group norms namely groups expectation effect, then with the help of potential normative force from this edutainment, form the psychological coercion force to college students, namely group pressure, it can let college students to gradually abandon and change the thinking and behavioral patterns which does not meet the requirement of group norms, to well blend into groups, promote the generation of group cohesion, thus educate and 
motivate the individuality, make him to form good character traits of the attitude motion of perseverance and intellect an so on, to well bred and distinguish between right and wrong.

Take the soldier Jiang Xiaoyu in "Fire Blue Blade" for example, he originally was a fisher who unworthily blend in underclass, he "reluctancely" joined in "the beast camp" which is famous of brutalising training, under the influence of the belief about self-sacrifice for national interests from veteran Liu Xiaoshan, he actively exercised the military wills, trained hard, won glory for the country at the Marrs International Scout competition, abandoned the team honors for national interests, formed dragon and shark squadrons, made the army's combat effectiveness enhanced. The process that the civilian heroes develop from simple soldiers to excellent soldiers always transfer noble belief on firm and indomitable, sacrifice and dedication, team spirit. His stories gave successful reference coordinates to college students which are about becoming excellent talent by hard effort and motivate and inspire them to constantly go beyond themselves and to overcome himself.

On account of this we can find that to the film and television works which has the significance of ideological and political education, both images and pictures of the movies, even a prop and a line unconsciously take on the task of ideological and political educators in many cases. college students enter into a ideological and political education objective environment with equal status, they selectively process these materials by using their living experience, emotion and thinking, ultimately draw their own value judgments. As one writer has said, "In the developing process of human civilization, besides the rockets and so on high-tech, morals and emotion are also components of human civilization, they are more subtly and ancient. It is very grievous that If our children have a very high level of science and technology, but their abilities to love and be loved gradually lose, in this sense, it is a educational project of plugging in the hi-tech wings and enhancing person' s quality to popularize the excellent film and television works." [6]

From this point of view, to ideological and political education for college students under the background of information, it must start from the actual situation of college students, constantly update the concept of ideological and political education, rich the educational content, explore new methods, bring function of time changing barometer to the main melody movie and TV drama and so on media forms into full play, further study its close relationship with the social trend of thought, lead college students' thought to develop in a healthy way, to realize double harvest of both the quality of education and social benefits.

\section{ACKNOWLEDGMENT}

This research was supported by the Ideological and Political Education Theory and Practice Project of Guangxi
Universities No.2012LSZ043, and by the Humane Social Research Project of Guangxi Universities No.SK13YB135.

\section{REFERENCES}

[1] Jintao HU. Persevere in advancing along the record to socialism with Chinese characteristics,strive to build a well-off society in an all-round way[N].People's Daily,2012-11-09(03).

[2] Zemin Jiang:Main task of propaganda and ideological fronts[EB/OL]http://cpc.people.com.cn/GB/64184/64185/180137/10818 726.html.

[3] Qingxian Sun,Renqiang Zhao. People oriented, To open up a new model of the ideological and political education for college students-on the Influence video teaching on the ideological and political education for college students[J].Theory Research,2009 (19) :202-203.

[4] Baoguo Cui,Jinzhu Lu,Xuhong Wang.2004-2005 development report on China's media industry[M].Social Sciences Academic Press,the 2001 edition.

[6] Guangtao Hu,Yi Liu.On How to do well the work of ideological and political education for college students by video education in the new era[J].Movie Review,2007（5）:79-81. 